\title{
Editorial
}

\section{La formación y el desarrollo profesional del profesorado de ciencias experimentales}

\section{A formação e o desenvolvimento profissional de professores de ciências experimentais}

\section{Dr. Vicente Mellado'}

En una época de cambios acelerados y de sociedades interdependientes por la globalización de la economía y el desarrollo de los sistemas de comunicación, la escuela es cada vez más compleja y heterogénea, ya que lo son los propios alumnos y el contexto social que la rodea. El aumento de la escolaridad obligatoria, la creciente interculturalidad, la conflictividad en las aulas, la pérdida del rol tradicional de autoridad del profesor, las nuevas tecnologías de información y comunicación, así como las consecuencias en la escuela de la crisis económica suponen un reto permanente para los profesores.

Los sistemas educativos intentan adaptarse a estos cambios realizando reformas curriculares, necesarias en muchos aspectos, aunque conservando antiguas estructuras de organización, y con la ingenua pretensión de que los cambios legislativos y curriculares bastan para producir una mejora en la enseñanza, sin tener en cuenta que el profesorado es la clave en la mejora cualitativa de los sistemas educativos y lo que verdaderamente determina el éxito o el fracaso de cualquier reforma o innovación curricular.

Los profesores no son técnicos que se limitan a aplicar las reformas y las instrucciones elaboradas por los expertos, sino que tienen concepciones, actitudes, emociones, valores y toman decisiones en función de múltiples factores y de su propia historia y situación personal, así como de los contextos profesionales y sociales en los que trabajan. Esta complejidad hace que las reformas educativas tengan escasa influencia en la vida del aula, si no dedican una atención especial a la formación inicial, a la etapa de iniciación a la docencia y al desarrollo profesional del profesorado.

1 Universidad de Extremadura, España 


\section{La formación inicial}

La formación inicial es una etapa importante, pero dentro de un continuo. Cuando el profesor en formación comienza su etapa universitaria, lo hace no solo con un bagaje de conocimientos, sino con unos valores, creencias, actitudes y emociones sobre la ciencia, la enseñanza y aprendizaje de las ciencias, y el propio rol del profesor, fruto de los muchos años de su propia escolaridad, que influirán en su formación.

La formación inicial tiene que integrar los conocimientos académicos, las concepciones personales y el conocimiento práctico, y contribuir a generar en los profesores en formación su modelo didáctico personal. Los conocimientos académicos proposicionales no se transfieren directamente a la práctica, por lo que la formación tiene que dar oportunidades a cada profesor de que, por medio de un proceso metacognitivo de reflexión, sea consciente de sus concepciones, conocimientos, actitudes, emociones y de su prácticas de aula al enseñar su materia específica, para que pueda autorregularlas y reestructurarlas y pueda ir desarrollando su propio conocimiento didáctico del contenido. El reto de esta formación inicial es dotar al profesorado de las herramientas que le permitan continuar formándose autónomamente durante su vida profesional en un mundo cambiante.

Las prácticas de enseñanza en conexión con las asignaturas de didáctica de las ciencias son un componente esencial en el desarrollo del modelo didáctico personal. En la formación inicial el conocimiento académico base necesario para la enseñanza (conocimiento del contenido, psicopedagógico general, de didáctica de las ciencias, etc.) se integra y transforma en el conocimiento didáctico del contenido durante la práctica de la enseñanza, enmarcado en el contexto particular en el que se realiza la enseñanza. Las primeras experiencias de enseñanza son emocionalmente muy fuertes y pueden ser traumáticas para los futuros profesores, que en esta etapa son especialmente vulnerables, lo que puede llevarle a adoptar estrategias didácticas defensivas, basadas en los modelos tradicionales que el futuro profesor haya vivido como alumno. El tutor de prácticas puede ayudar al futuro profesor a superar las dificultades, ya que es un potente modelo de rol, y puede ejercer una fuerte influencia en la dirección de su futuro desarrollo profesional. Por ello es fundamental que los tutores estén comprometidos con la formación y la colaboración académica entre las instituciones dedicadas a la formación inicial y los centros donde los profesores realizan las prácticas de enseñanza.

Si los profesores en formación toman como referencia, positiva o negativa, para la enseñanza de las ciencias, a los profesores que han tenido a lo largo de su escolaridad, la metodología que se utilice durante la formación inicial por los formadores tiene que ser coherente con los modelos teóricos de formación que propugnan. En caso contrario, los estudiantes para profesores aprenderán más de lo que ven hacer en clase, que de lo que se les dice que hay que hacer. 


\section{La iniciación a la docencia}

Otra importante etapa, aunque la más olvidada, es la de iniciación a la docencia. En esta fase es cuando más se fijan las rutinas y estrategias de enseñanza. Sin embargo en muchos casos a los profesores principiantes se les asignan los cursos más difíciles y conflictivos, algo que no se da en otras profesiones, y los principiantes se ven sometidos a numerosas tensiones, dilemas y sobrecarga de trabajo. Las emociones negativas en las primeras experiencias autónomas de enseñanza como ansiedad, inseguridad, irritación o decepción, suponen un obstáculo para la innovación y pueden fijar estrategias conductistas, dirigidas hacia el control y la supervivencia, con las que los profesores se sienten emocionalmente más seguros, pero que son muy resistentes al cambio en el futuro.

Sin embargo en los primeros años de docencia es cuando los profesores tienen más capacidad de cambio hacia estrategias innovadoras. Pero para que la innovación resulte provechosa y con continuidad, el principiante tiene que sentir que las estrategias didácticas que pone en marcha son eficaces para la enseñanza de su materia y para el aprendizaje de sus alumnos, y en muchos casos por sí solo no tiene el tiempo, los conocimientos ni los recursos necesarios para llevarlas a cabo. La participación en actividades de investigación e innovación en equipos de coenseñanza y el trabajo en colaboración con profesores expertos, es un apoyo profesional y emocional que ayuda a los principiantes a compartir sus problemas y sus dudas y a consolidar los cambios.

Para los profesores expertos, ser tutores de profesores en formación o mentores de los profesores principiantes puede convertirse en una experiencia positiva de desarrollo profesional. Puede significar para los tutores y mentores trabajar en colaboración con docentes de distintos niveles, elaborar proyectos conjuntos de investigación e innovación, analizar situaciones de enseñanza y aprendizaje de las ciencias en el contexto real de la clase, y otras muchas actividades que ayudan al profesor a salir del aislamiento y a trabajar en colaboración.

\section{El desarrollo profesional}

Los profesores con experiencia tienen creencias y conocimientos prácticos personales muy estables y consolidados a lo largo de su actividad profesional, y muy resistentes al cambio. Además tienen poco tiempo disponible y la formación les supone un esfuerzo añadido y una sobrecarga de trabajo, para algo que en muchas ocasiones consideran irrelevante para lo que tienen que hacer diariamente en el aula.

En estos educadores, la formación no hay que plantearla como un cambio de modelo didáctico, sobrevalorando lo nuevo y rechazando lo viejo; más bien hay que asumirla como un proceso interno de crecimiento y de desarrollo gradual a partir de lo que ya piensan y hacen, de los problemas reales de enseñanza y aprendizaje de las ciencias, de las preocupaciones cotidianas del profesor y del 
contexto en el que desarrolla su actividad. Todo ello potenciando y apoyando la motivación, la confianza, la disponibilidad, la colaboración y el compromiso de los profesores en su propio desarrollo profesional.

El desarrollo profesional tiene que ir unido al personal y social, teniendo en cuenta los aspectos afectivos, fomentando la colaboración constructiva, fortaleciendo la cultura de los centros y construyendo sobre las buenas prácticas que los profesores estén ya realizando. Esto requiere más tiempo y muchos apoyos sostenidos, para que el profesor pueda observar la mejora en el aprendizaje de los estudiantes y percibir la formación como una experiencia educativa válida para sí mismo, para sus clases y para su centro.

En el desarrollo profesional hay que integrar los conocimientos académicos, las concepciones, las actitudes, las emociones, los valores y las prácticas docentes del profesor al enseñar su materia, pero el eje de la formación tiene que ser la didáctica de las ciencias, pues el contenido a enseñar condiciona los roles del profesor y las estrategias de enseñanza. La investigación/acción, en colaboración con otros profesores de situaciones y problemas relevantes de la enseñanza y aprendizaje de las ciencias de interés de sus propias clases, es a medio y largo plazo una extraordinaria estrategia de desarrollo profesional.

El desarrollo profesional se estimula por procesos sucesivos de autorregulación metacognitiva del profesor basados en la reflexión, comprensión y control de lo que piensa, siente y hace, y de los propios cambios que el profesor realice. Tomar conciencia de los problemas de enseñanza y aprendizaje que pueden ser mejorables, elaborar nuevas actividades, materiales y propuestas de enseñanza, ponerlos en práctica en el propio contexto, reflexionar sucesivamente sobre su enseñanza y sobre los resultados en el aprendizaje de los estudiantes, contrastarlas con otros casos, y volver a revisarlas y a autorregularlas.

Para terminar, la crisis económica ha sumido a muchos ciudadanos, y especialmente a muchos jóvenes, en el desempleo y en la pobreza. Sin embargo la escuela sigue siendo una pieza insustituible para formar ciudadanos cultos, responsables, emprendedores y comprometidos con el desarrollo económico, social, humano y medioambiental de nuestras sociedades. Se equivocan los gobiernos que utilizan la crisis económica como coartada para realizar recortes económicos en educación y en los programas de formación del profesorado, pues la educación sigue siendo el valor más importante para garantizar un futuro de progreso y de igualdad de oportunidades para todos los ciudadanos. 